\title{
Guideline update for the performance of fusion procedures for degenerative disease of the lumbar spine. Part 8: Lumbar fusion for disc herniation and radiculopathy
}

\author{
Jeffrey C. Wang, M.D. ${ }^{1}$ Andrew T. Dailey, M.D. ${ }^{2}$ Praveen V. Mummaneni, M.D. ${ }^{3}$ \\ Zoher Ghogawala, M.D., ${ }^{4}$ Daniel K. Resnick, M.D., ${ }^{5}$ William C. WatTers III, M.D., 6 \\ Michael W. Groff, M.D., 7 Tanvir F. Choudhri, M.D., ${ }^{8}$ Jason C. Eck, D.O., M.S., 9 \\ Alok Sharan, M.D., ${ }^{10}$ SanJay S. Dhall, M.D., ${ }^{3}$ And Michael G. Kaiser, M.D. ${ }^{11}$ \\ ${ }^{1}$ Department of Orthopaedic Surgery, Keck School of Medicine, University of Southern California, Los \\ Angeles, California; ${ }^{2}$ Department of Neurosurgery, University of Utah, Salt Lake City, Utah; ${ }^{3}$ Department \\ of Neurological Surgery, University of California, San Francisco, California; ${ }^{4}$ Alan and Jacqueline Stuart \\ Spine Research Center, Department of Neurosurgery, Lahey Clinic, Burlington, and Tufts University School \\ of Medicine, Boston, Massachusetts; ${ }^{5}$ Department of Neurosurgery, University of Wisconsin, Madison, \\ Wisconsin; ${ }^{6}$ Bone and Joint Clinic of Houston, Houston, Texas; ${ }^{7}$ Department of Neurosurgery, Brigham \\ and Women's Hospital, Boston, Massachusetts; ${ }^{8}$ Department of Neurosurgery, Icahn School of Medicine at \\ Mount Sinai, New York, New York; ${ }^{9}$ Center for Sports Medicine and Orthopaedics, Chattanooga, Tennessee; \\ ${ }^{10}$ Department of Orthopaedic Surgery, Montefiore Medical Center, Albert Einstein College of Medicine, \\ Bronx, New York; and ${ }^{11}$ Department of Neurosurgery, Columbia University, New York, New York
}

Patients suffering from a lumbar herniated disc will typically present with signs and symptoms consistent with radiculopathy. They may also have low-back pain, however, and the source of this pain is less certain, as it may be from the degenerative process that led to the herniation. The surgical alternative of choice remains a lumbar discectomy, but fusions have been performed for both primary and recurrent disc herniations. In the original guidelines, the inclusion of a fusion for routine discectomies was not recommended. This recommendation continues to be supported by more recent evidence. Based on low-level evidence, the incorporation of a lumbar fusion may be considered an option when a herniation is associated with evidence of spinal instability, chronic low-back pain, and/or severe degenerative changes, or if the patient participates in heavy manual labor. For recurrent disc herniations, there is low-level evidence to support the inclusion of lumbar fusion for patients with evidence of instability or chronic low-back pain. (http://thejns.org/doi/abs/10.3171/2014.4.SPINE14271)

KEY WORDS - fusion • lumbar spine - herniated disc • practice guidelines

\section{Recommendations}

There is no evidence that conflicts with the previous recommendations formulated from the first generation of the Lumbar Fusion Guidelines.

\section{Grade C}

Lumbar spinal fusion is not recommended as a routine treatment following primary disc excision in patients with isolated herniated lumbar discs causing radiculopathy (Level IV evidence).

Lumbar spinal fusion is a potential option in patients with herniated discs who have evidence of significant

Abbreviations used in this paper: $\mathrm{JOA}=$ Japanese Orthopaedic Association; LHNP = lumbar herniated nucleus pulposus; ODI = Oswestry Disability Index. chronic axial back pain, work as manual laborers, have severe degenerative changes, or have instability associated with radiculopathy caused by herniated lumbar discs (Level IV evidence).

Reoperative discectomy and fusion is a treatment option in patients with recurrent disc herniations associated with instability or chronic axial low back pain (Level III and IV evidence).

\section{Rationale}

Herniation of a lumbar disc will typically manifest with radicular signs and symptoms consistent with the spinal nerve under compression. Less specific complaints of low-back pain, presumably from the degeneration associated with the disc herniation, may also be present. To address the primary pathology, which is the compression 
Part 8: Lumbar fusion for disc herniation and radiculopathy

of the spinal nerve, lumbar discectomy has become the established surgical procedure in cases in which conservative management fails to provide relief.

Although spinal fusion is routinely performed for lumbar instability or low-back pain associated with severe disc degeneration, it has been used for patients presenting with either a primary or recurrent lumbar herniated nucleus pulposus (LHNP) and this application has been described in the literature. Incorporating a fusion during a routine discectomy would increase the complexity of the case, prolong the surgical time, and potentially increase complication rates, without proven medical necessity. As indicated in the first generation of the Lumbar Fusion Guidelines, justification for fusion under these circumstances is lacking. ${ }^{15}$ The purpose of this update is to examine the more recent literature investigating the role of fusion in the operative management of patients presenting with radiculopathy and/or back pain secondary to a LHNP.

\section{Search Criteria}

A computerized search of the database of the National Library of Medicine from July 2003 to December 2011 was conducted using the search terms ((("Lumbosacral Region"[MeSH] OR "Lumbar Vertebrae"[MeSH]) AND "Spinal Fusion"[MeSH]) OR "lumbar fusion"[All Fields] OR ("lumbar"[title] AND "fusion"[title])) AND ("Radiculopathy"[MeSH] OR radiculopathy[title] OR “intervertebral disk displacement"[title] OR "herniated"[title] OR "intervertebral disc displacement"[title] OR "herniation”[title]) AND ((“2003”[PDAT]: “3000”[PDAT]) AND "humans"[MeSH] AND English[lang]). The search was restricted to the English language. This yielded a total of 74 references. The titles and abstracts of each of these references were reviewed, and papers not concerned with the use of fusion with lumbar disc herniations were discarded. References were identified that provided either direct or supporting evidence relevant to the use of fusion as a treatment for lumbar disc herniations. These papers were obtained and reviewed, and relevant references from the bibliographies of these papers were identified. Relevant papers providing Level IV or better evidence are summarized in the evidentiary table. Other papers providing supportive data are shown in the reference section.

\section{Scientific Foundation}

\section{Primary Herniated Disc With Radiculopathy}

In the first generation of the Lumbar Fusion Guidelines, Resnick et al. examined the role of fusion for patients with radiculopathy and an LHNP. ${ }^{15}$ The authors performed a literature review of studies of Level IV or better quality and determined that the routine use of fusion in conjunction with a disc excision for primary LHNP is not recommended. The outcome following decompressive surgery for a patient presenting with an LHNP and radiculopathy, whether primary or recurrent, has been demonstrated in numerous publications..$^{10,11}$ There are a plethora of studies reporting excellent results and outcomes for patients with primary disc herniations having decompressive surgeries without fusion, and many of these studies are Level I and II studies. ${ }^{1-4,14,17,20-23}$

This current review will examine the studies investigating fusion as compared with discectomy alone to determine if evidence exists for the addition of fusion in patients with primary disc herniation. Advocates for fusion during the index discectomy claim that stabilizing the segment may prevent late-onset instability and the development of chronic low-back pain. Although several studies have demonstrated that the occurrence of instability following discectomy is associated with less-favorable outcomes, the incidence is relatively low, and therefore routine fusion is not recommended..$^{15,16}$

Some of the studies used to support this recommendation in the past review were examined once again. Takeshima et al. performed a retrospective review of cases involving patients undergoing surgery for primary disc herniations. ${ }^{19}$ Of 95 patients, 44 underwent discectomy alone (after 1990) and 51 underwent discectomy and fusion (between 1986 and 1989), with follow-up averaging 7 years and assessments using the Japanese Orthopaedic Association (JOA) rating scale. There was no statistically significant difference between the 2 groups $(p=0.31)$. This study provides Level III evidence that the routine use of a noninstrumented posterolateral fusion does not improve functional outcome in patients treated with lumbar discectomy. In another study, Donceel and DuBois reviewed a series of 3956 cases involving patients with disc herniations treated with either discectomy $(n=3670)$ or discectomy and fusion $(n=286) .{ }^{6}$ They found that $70 \%$ of the discectomy-alone group were able to resume their preoperative work level at 1 year after surgery, compared with $45 \%$ of the fusion group. The authors noted that the fusion group tended to have more significant symptoms and more complex preoperative histories. This retrospective review provides Level IV evidence suggesting that the addition of fusion does not improve patient outcomes. There were no further studies found that compared discectomy alone to discectomy and fusion. This is likely due to the large number of studies demonstrating excellent outcomes without fusion in this patient population with an isolated LHNP.

\section{Primary Herniated Lumbar Disc Associated With Low-Back Pain/Instability}

Fusion has also been recommended for patients presenting with new-onset LHNP and radiculopathy in the presence of axial low-back pain or radiographic instability. The previous review concluded that there was Level III evidence to support the use of posterior fusion at the time of initial discectomy surgery in manual laborers or those with significant preoperative axial low-back pain..$^{15}$ Matsunaga et al. reported the results of a retrospective study of 80 cases involving manual laborers treated via either open or percutaneous discectomy $(n=51)$ or an open discectomy and fusion $(n=29) .{ }^{12}$ They found that at the 1-year point $53 \%$ of the patients in the discectomy group and $89 \%$ of those in the fusion group were able to resume and maintain preoperative manual labor work activities. Although the discectomy patients did return to 


\section{J. C. Wang et al.}

work earlier (12 weeks after surgery) than those in the fusion group (25 weeks after surgery), $22 \%$ of the discectomy group could not maintain their work activities due to "lumbar fatigue." These authors concluded that the addition of fusion should be considered in manual laborers, as it seems to provide a better chance of returning to and staying at their preoperative level of function. The paper is judged to provide Level IV evidence supporting the use of posterolateral fusion at the time of discectomy to improve return to work rates in patients involved in heavy manual labor work activities (see Table 1).

Eie reported on 259 patients with disc herniations who were treated either by discectomy alone $(n=119)$ or by discectomy and noninstrumented posterolateral fusion $(n=68) .^{7}$ At 6 years postsurgery, $76 \%$ of the discectomyalone group reported satisfaction compared with $85 \%$ of the fusion group. The discectomy-alone patients reported a significantly higher incidence of pain recurrence $(27 \%$ of patients) compared with the discectomy plus fusion group ( $15 \%$ of patients, $p<0.01)$. This is another Level IV paper supporting the use of fusion at the time of discectomy, especially in patients with significant low-back pain, as they have a higher chance of having pain in later years without a concomitant fusion (see Table 1).

Newer studies reviewed since the prior recommendations were published support the use of fusion for patients with significant preoperative low-back pain and those with existing instability. Satoh et al. published a retrospective review of 174 cases involving patients with disc herniations treated with fusion and 177 involving patients treated with discectomy alone. ${ }^{18}$ All patients had at least 5 years of follow-up. Fusion criteria included either a massive disc herniation, as defined by a complete myelographic block on a CT myelogram, or segmental instability, as defined by an anterolisthesis of greater than $3 \mathrm{~mm}$ with or without local kyphosis of more than $5^{\circ}$ on a flexion lateral radiograph. Patients were assessed on a clinical outcomes questionnaire with a scale consisting of excellent, good, fair, and poor, which appeared to be a modification of Odom's criteria. Patients undergoing a fusion demonstrated significantly better outcomes with respect to low-back pain. The frequency of revision surgery was significantly higher in patients who did not receive a fusion, but met the criteria for fusion. Interestingly, those patients who did not fulfill the criteria for fusion but had a fusion surgery also had significantly better results in terms of low-back pain scores compared with those without fusions. The authors concluded with this Level IV study that patients with disc herniations and instability or massive herniations can be successfully treated with fusion at the time of primary discectomy.

\section{Recurrent Disc Herniation}

The previous Lumbar Fusion Guidelines concluded that reoperative discectomy is recommended as a treatment option in patients with recurrent disc herniations and radiculopathy. ${ }^{15}$ For a first-time recurrence, this recommendation continues to be supported by more recent publications. Fu et al., in a retrospective Level III review, investigated the outcome in 41 cases of recurrent lumbar disc herniation. ${ }^{8}$ In this study, 23 patients underwent a revision discectomy and 18 underwent a revision discectomy with posterolateral instrumentation and fusion. ${ }^{8}$ The minimum follow-up for both cohorts was 60 months, and patients were evaluated using the JOA scores for lowback pain. The clinical outcome was excellent or good in $78.3 \%$ of the discectomy cohort and $83.3 \%$ of the fusion group. There was no significant difference in clinical outcome parameters between the 2 groups including lowback pain scores, but intraoperative blood loss, length of surgery, and length of hospitalization were significantly less in the nonfusion group. This study provides Level III evidence that in patients presenting with an isolated recurrent herniation with sciatica, disc excision alone without fusion is recommended. This study had very few patients lost to follow-up and was from a single-center with excellent longer-term follow-up.

Fusion at the time of revision discectomy has been more consistently recommended as a treatment option for patients with associated lumbar instability, radiographic degenerative changes, and/or chronic axial low-back pain. ${ }^{15}$ This recommendation in the previous guidelines was based on several studies. Huang and Chen reported on 28 patients undergoing posterior interbody fusion $(8$ with recurrent disc herniations and 10 with low-grade spondylolisthesis). ${ }^{9}$ These patients all had significant degenerative changes and some had spondylolisthesis. The average follow-up was 14 months, and all patients had pedicle screw fixation. Overall, 93\% of the patients were satisfied with their condition, and $82 \%$ were considered to have achieved radiographic fusion. Of the 8 patients with recurrent disc herniations, 6 had excellent or good outcomes, and 2 had fair outcomes. In another study, Chitnavis and colleagues reported on a group of patients with recurrent disc herniations with symptoms of back pain or signs of instability, who were treated with posterior decompression and interbody fusion. ${ }^{5}$ Of a total of 50 patients with 6 months to 5 years of follow-up, $92 \%$ improved after surgery and $90 \%$ were very satisfied with their results. This study provides Level IV evidence demonstrating good results with fusion in these patients with recurrent disc herniations with instability and/or axial low-back pain. There is a paucity of more recent evidence to support or refute the previous conclusions from the initial publication of the Lumbar Fusion Guidelines. The majority of these studies were case series and not comparative studies looking at discectomy alone versus discectomy and fusion. ${ }^{13}$

\section{Summary}

Based on the recent literature reviewed, there does not appear to be evidence to support the routine use of fusion at the time of an index discectomy operation. There remains conflicting Level III and IV evidence regarding the potential benefit of the addition of fusion in certain situations; however, the increase in morbidity, cost, and potential complications associated with the use of fusion are not justified in routine situations. Patients with demonstrated preoperative instability and significant chronic low-back pain in addition to radicular symptoms may be 
Part 8: Lumbar fusion for disc herniation and radiculopathy

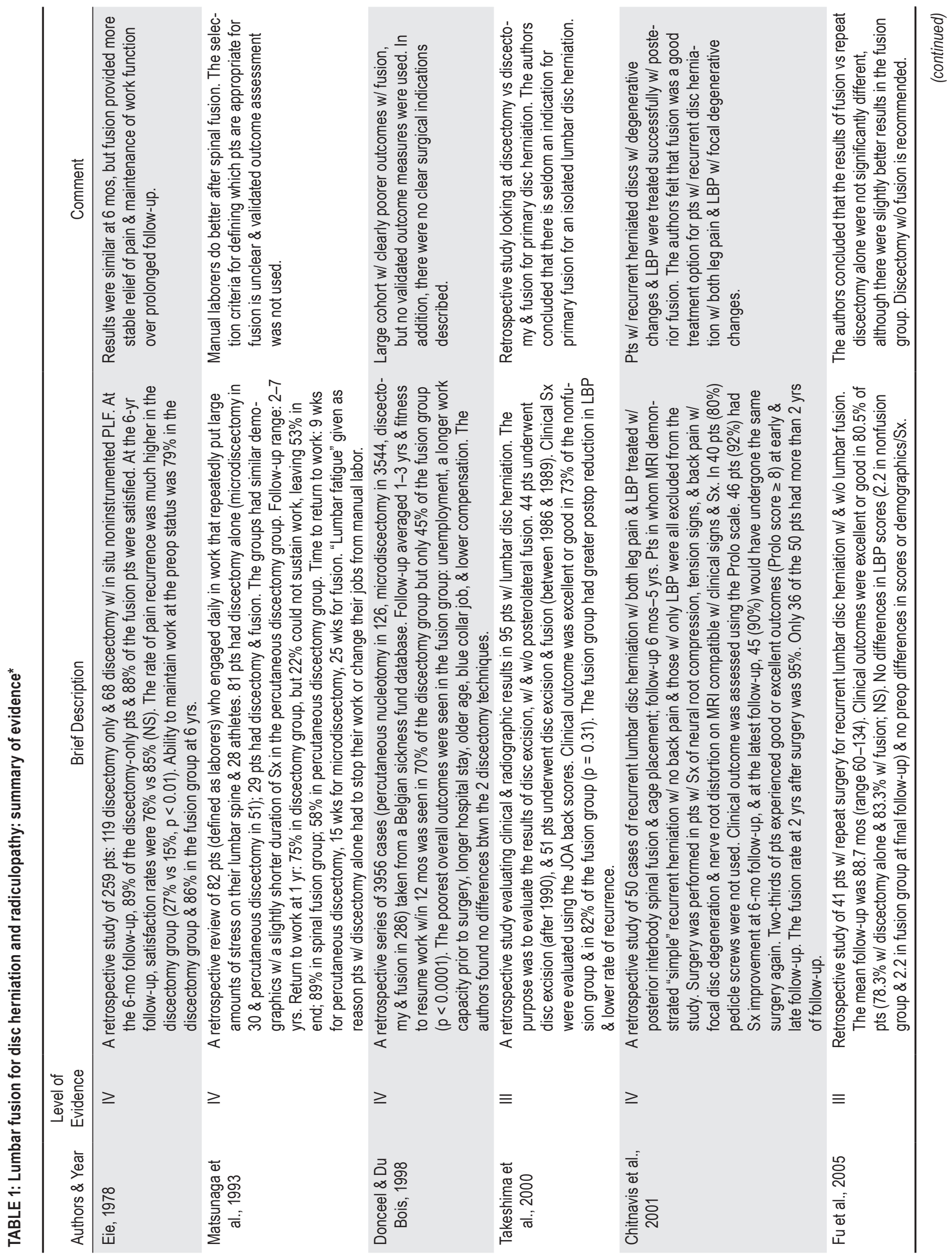




\section{J. C. Wang et al.}

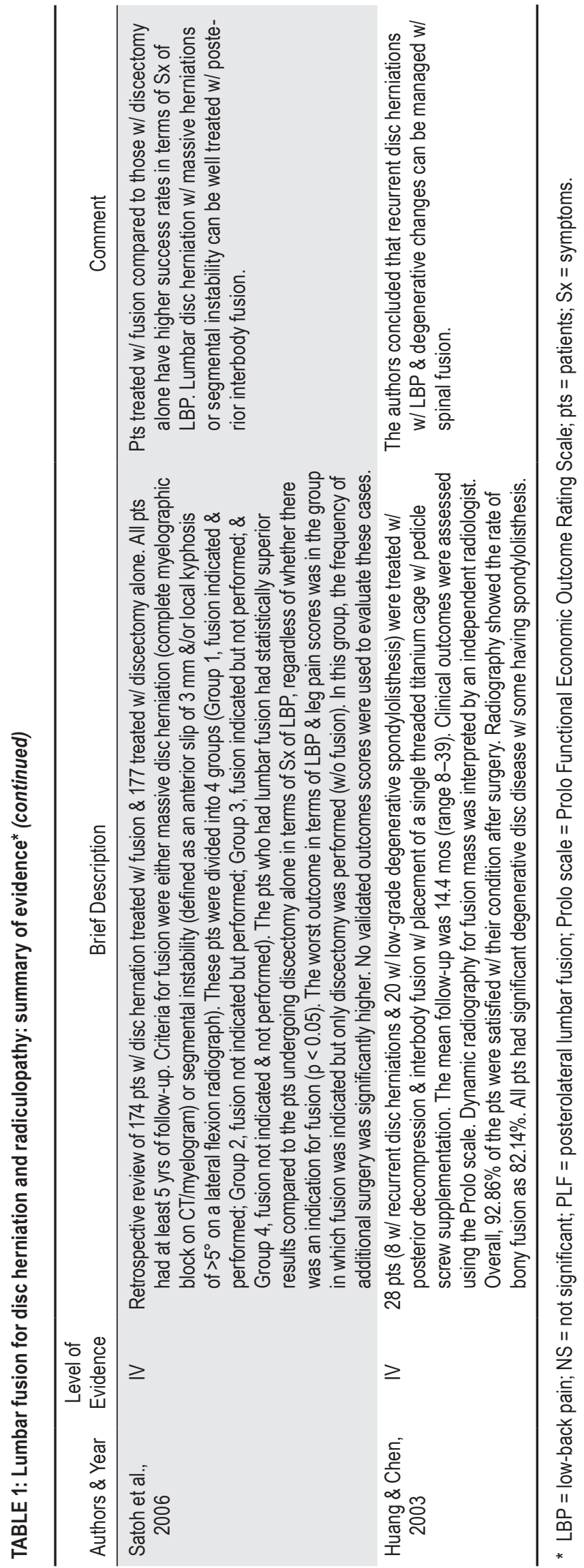

candidates for fusion at the time of primary disc excision. Patients with recurrent disc herniations have been treated successfully with repeated excision as well as with excision and fusion. In patients with significant spinal deformity, instability, or associated chronic low-back pain, consideration of fusion is reasonable.

\section{Key Issues for Future Investigation}

The fact that fusion surgery is not required following a routine, index discectomy is well established, but further investigation to define various radiographic findings predicative of progressive disease would be very valuable. The utility of fusion for recurrent disc herniation remains controversial, and further investigation incorporating improved study design will be required to address this issue.

\section{Acknowledgments}

We would like to acknowledge the AANS/CNS Joint Guidelines Committee (JGC) for their review, comments, and suggestions; Laura Mitchell, CNS Guidelines Project Manager, for her organizational assistance; and Linda O'Dwyer, medical librarian, for assistance with the literature searches. We would also like to acknowledge the following individual JGC members for their contributions throughout the review process: Timothy Ryken, M.D.; Kevin Cockroft, M.D.; Sepideh Amin-Hanjani, M.D.; Steven N. Kalkanis, M.D.; John O’Toole, M.D., M.S.; Steven Casha, M.D., Ph.D.; Aaron Filler, M.D., Ph.D., F.R.C.S.; Daniel Hoh, M.D.; Steven Hwang, M.D.; Todd McCall, M.D.; Jeffrey J. Olson, M.D.; Julie Pilitsis, M.D., Ph.D.; Joshua Rosenow, M.D.; and Christopher Winfree, M.D.

\section{Disclosure}

Administrative costs of this project were funded by the Congress of Neurological Surgeons and the Joint Section on Disorders of the Spine and Peripheral Nerves of the American Association of Neurological Surgeons and Congress of Neurological Surgeons. No author received payment or honorarium for time devoted to this project. Dr. Ghogawala receives grants from the Patient Centered Outcomes Research Institute (PCORI) and the National Institutes of Health (NIH). Dr. Groff is a consultant for DePuy Spine and EBI Spine. Dr. Mummaneni owns stock in Spinicity and receives honoraria from DePuy Spine and Globus and royalties from DePuy Spine, Quality Medical Publishers, and Thieme Publishing. Dr. Wang owns stock in Bone Biologics, AxioMed, Amedica, CoreSpine, Expanding Orthopedics, Pioneer, Syndicom, VG Innovations, PearlDiver, Flexuspine, Axis, FzioMed, Benvenue, Promethean, Nexgen, ElectroCore, and Surgitech and holds patents with and receives royalties from Biomet, Stryker, SeaSpine, Aesculap, Osprey, Amedica, Synthes, and Alphatec. The authors report no other potential conflicts of interest concerning the materials or methods used in this study or the findings specified in this paper.

Author contributions to the study and manuscript preparation include the following. Acquisition of data: all authors. Analysis and interpretation of data: all authors. Drafting the article: Wang. Critically revising the article: all authors. Reviewed submitted version of manuscript: all authors. Approved the final version of the manuscript on behalf of all authors: Wang. Study supervision: Kaiser.

\section{References}

1. Anderson PA, McCormick PC, Angevine PD: Randomized controlled trials of the treatment of lumbar disk herniation: 1983-2007. J Am Acad Orthop Surg 16:566-573, 2008 


\section{Part 8: Lumbar fusion for disc herniation and radiculopathy}

2. Arts MP, Brand R, van den Akker ME, Koes BW, Bartels RH, Tan WF, et al: Tubular diskectomy vs conventional microdiskectomy for the treatment of lumbar disk herniation: 2-year results of a double-blind randomized controlled trial. Neurosurgery 69:135-144, 2011

3. Atlas SJ, Keller RB, Wu YA, Deyo RA, Singer DE: Longterm outcomes of surgical and nonsurgical management of sciatica secondary to a lumbar disc herniation: 10 year results from the Maine Lumbar Spine Study. Spine (Phila Pa 1976) 30:927-935, 2005

4. Bruggeman AJ, Decker RC: Surgical treatment and outcomes of lumbar radiculopathy. Phys Med Rehabil Clin N Am 22:161-177, 2011

5. Chitnavis B, Barbagallo G, Selway R, Dardis R, Hussain A, Gullan R: Posterior lumbar interbody fusion for revision disc surgery: review of 50 cases in which carbon fiber cages were implanted. J Neurosurg 95 (2 Suppl):190-195, 2001

6. Donceel P, Du Bois M: Fitness for work after surgery for lumbar disc herniation: a retrospective study. Eur Spine J 7:29-35, 1998

7. Eie N: Comparison of the results in patients operated upon for ruptured lumbar discs with and without spinal fusion. Acta Neurochir (Wien) 41:107-113, 1978

8. Fu TS, Lai PL, Tsai TT, Niu CC, Chen LH, Chen WJ: Longterm results of disc excision for recurrent lumbar disc herniation with or without posterolateral fusion. Spine (Phila Pa 1976) 30:2830-2834, 2005

9. Huang KF, Chen TY: Clinical results of a single central interbody fusion cage and transpedicle screws fixation for recurrent herniated lumbar disc and low-grade spondylolisthesis. Chang Gung Med J 26:170-177, 2003

10. Kast E, Oberle J, Richter HP, Börm W: Success of simple sequestrectomy in lumbar spine surgery depends on the competence of the fibrous ring: a prospective controlled study of 168 patients. Spine (Phila Pa 1976) 33:1567-1571, 2008

11. Kim JS, Lee SH, Moon KH, Lee HY: Surgical results of the oblique paraspinal approach in upper lumbar disc herniation and thoracolumbar junction. Neurosurgery 65:95-99, 2009

12. Matsunaga S, Sakou T, Taketomi E, Ijiri K: Comparison of operative results of lumbar disc herniation in manual laborers and athletes. Spine (Phila Pa 1976) 18:2222-2226, 1993

13. Niemeyer T, Halm H, Hackenberg L, Liljenqvist U, Bövingloh AS: Post-discectomy syndrome treated with lumbar interbody fusion. Int Orthop 30:163-166, 2006

14. Pearson AM, Blood EA, Frymoyer JW, Herkowitz H, Abdu WA, Woodward R, et al: SPORT lumbar intervertebral disk herniation and back pain: does treatment, location, or morphology matter? Spine (Phila Pa 1976) 33:428-435, 2008
15. Resnick DK, Choudhri TF, Dailey AT, Groff MW, Khoo L, Matz PG, et al: Guidelines for the performance of fusion procedures for degenerative disease of the lumbar spine. Part 8: lumbar fusion for disc herniation and radiculopathy. J Neurosurg Spine 2:673-678, 2005

16. Resnick DK, Groff MC: Evidence-based guidelines in lumbar spine surgery. Prog Neurol Surg 19:123-134, 2006

17. Rihn JA, Hilibrand AS, Radcliff K, Kurd M, Lurie J, Blood E, et al: Duration of symptoms resulting from lumbar disc herniation: effect on treatment outcomes: analysis of the Spine Patient Outcomes Research Trial (SPORT). J Bone Joint Surg Am 93:1906-1914, 2011

18. Satoh I, Yonenobu K, Hosono N, Ohwada T, Fuji T, Yoshikawa $\mathrm{H}$ : Indication of posterior lumbar interbody fusion for lumbar disc herniation. J Spinal Disord Tech 19:104-108, 2006

19. Takeshima T, Kambara K, Miyata S, Ueda Y, Tamai S: Clinical and radiographic evaluation of disc excision for lumbar disc herniation with and without posterolateral fusion. Spine (Phila Pa 1976) 25:450-456, 2000

20. Tosteson AN, Skinner JS, Tosteson TD, Lurie JD, Andersson GB, Berven S, et al: The cost effectiveness of surgical versus nonoperative treatment for lumbar disc herniation over two years: evidence from the Spine Patient Outcomes Research Trial (SPORT). Spine (Phila Pa 1976) 33:2108-2115, 2008

21. Weinstein JN, Lurie JD, Tosteson TD, Skinner JS, Hanscom B, Tosteson AN, et al: Surgical vs nonoperative treatment for lumbar disk herniation: the Spine Patient Outcomes Research Trial (SPORT) observational cohort. JAMA 296:2451-2459, 2006

22. Weinstein JN, Lurie JD, Tosteson TD, Tosteson AN, Blood EA, Abdu WA, et al: Surgical versus nonoperative treatment for lumbar disc herniation: four-year results for the Spine Patient Outcomes Research Trial (SPORT). Spine (Phila Pa 1976) 33:2789-2800, 2008

23. Weinstein JN, Tosteson TD, Lurie JD, Tosteson AN, Hanscom B, Skinner JS, et al: Surgical vs nonoperative treatment for lumbar disk herniation. The Spine Patient Outcomes Research Trial (SPORT): a randomized trial. JAMA 296:2441-2450, 2006

Manuscript submitted March 13, 2014

Accepted April 3, 2014.

Please include this information when citing this paper: DOI: 10.3171/2014.4.SPINE14271.

Address correspondence to: Michael G. Kaiser, M.D., Columbia University, Neurological Surgery, The Neurological Institute, 710 W. 168th St., New York, NY 10032.email: mgk7@columbia.edu. 